\title{
Review on the Influences of: Resource Mobilization, Patriarchy System and Policy Implementation on Gender Mainstreaming; the Case of Ethiopia
}

\author{
Gutema Adem, Sultan Mohammed \\ College of Social Science and Humanities, Madda Walabu University, Bale Robe, Ethiopia \\ Email:gutemaadem81@gmail.com, sulxaanmahmud@gmail.com
}

How to cite this paper: Adem, G. and Mohammed, S. (2020) Review on the Influences of: Resource Mobilization, Patriarchy System and Policy Implementation on Gender Mainstreaming; the Case of Ethiopia. Open Access Library Journal, 7: e6743. https://doi.org/10.4236/oalib.1106743

Received: August 24, 2020

Accepted: September 24, 2020

Published: September 27, 2020

Copyright $\odot 2020$ by author(s) and Open Access Library Inc.

This work is licensed under the Creative Commons Attribution International License (CC BY 4.0).

http://creativecommons.org/licenses/by/4.0/ (c) (i) Open Access

\begin{abstract}
The objective of this article is to critically review the effects of Resource Mobilization, Patriarchy System and Policy Implementation on Gender Mainstreaming. To effectively tackle gender inequalities, the structures and systems which act as root causes of gender inequality must be addressed. To do this, there should be the mainstream of gender concerns into all policies, programmes and service delivery. Gender Mainstreaming challenges decision-makers to question the assumption that policies and programmes affect everyone in the same way. Thus, the general objective of this article is to critically review the effect of resources mobilization, policy implementation gap and patriarchal ideology on gender mainstreaming. In order to achieve the intended goal, the reviewers critically and systematically reviewed different researches, articles and legal documents. Finally, the reviewers concluded that mainstreaming gender cannot possible without the prerequisites like sufficient resources mobilization, deconstructing the ideology of male domination and filling the policy implementation gap which is the common problem in Ethiopia.
\end{abstract}

\section{Subject Areas}

Sociology

\section{Keywords}

Influences, Resource Mobilization, Patriarchy System, Policy

Implementation, Gender Mainstreaming, Women 


\section{Introduction}

It is inevitable that progress towards achieving greater equality between women and men will require changes at many levels, including changes in attitudes and relationships, changes in institutions and legal frameworks, changes in economic institutions, and changes in political decision-making structures. Thus, what is common to mainstreaming in all sectors or development issues is that a concern for gender equality needs to be brought to the mainstream rather than dealing with add on.

Globally, feminist theorists agreed on gender inequalities but their points of their differences are how to eliminate gender inequalities. Thus, for all feminist scholars gender inequalities should be deconstructed and have to become to the assertive point. To do so, all feminist theorists agreed up on the following points;

- Challenging the cultures that discriminate women,

- Refusing the inequalities between women and men manifested in all aspects of life.

- Challenging discriminatory laws and statue

Studies indicate that the government of Ethiopia is recognized the right of women and declares its commitment to gender equality (Ogato, 2013) [1]. Though progress has been made there are still policy implementation challenges, as it relates to changes in attitudes and cultural values which take time to evolve. For instance article 34(1) of Federal Democratic Republic of Ethiopian Constitution states that men and women, who have attained marriageable age as defined by law, have the right to marry and found a family. Furthermore, it is clearly stated that both women and men have equal rights while entering into, during marriage and at the time of divorce and article 34 (2) ensures that marriage should be entered into only with the free and full consent of the intending spouses but given the traditional environment in which women have little or no rights in deciding on such matters, it is difficult, if not impossible, for women to realize and enjoy these rights. It is also difficult to measure whether or not the marriage entered into only with the free and full consent of the intending spouses, because the consent can be influenced by various visible and invisible factors in the process of giving it and this in turn affects its practicability.

Article 34 (4 and 5) FDRE constitution extends recognition to marriage concluded under systems of religious or customary laws and it does not exclude the customary or religious adjudication of disputes relating to personal and family laws, with the consent of the parties to dispute. This recognition is a potential threat that perpetuates the existing gender inequalities in the society. Because, intentionally or unintentionally, these laws usually work in the way that sustains and maintains the subordination and oppression of women. Those religious and customary practices in most cultures of Ethiopia, every girl is expected to be virgin up on her first marriage otherwise she would be beaten and tortured by the husband and disgracefully sent back to her parents with consequent shame on them, too. Her husband on the other hand is not expected to be virgin up on 
marriage. Because of the existence of patriarchal system of the society and poor implementation, the provision of equality of women in the marital, personal and family issues may not be resulted in the valuable realities on the ground.

The Pathfinder found that the policies and structures the government expands in order to promote and support gender mainstreaming in all sectors are still far from bringing tangible changes on the lives of women and girls. Although some of the cultures are important for the promotion of development through enhancement of women's participation in all aspects of life, there are most traditions and values that negatively affect women's decision making. Different scholars and organizations define the term gender mainstreaming in different ways (Tesfayenesh, L, 2008) [2]. There are traditions and norms encourage only men's superiority and support the men as the only potent who can govern all political and economic affairs. These consider women as powerless people with poor idea and inferior to men (Pathfinder, 2007) [3].

\section{Highlighted Women Situation in Africa and Ethiopia}

The global evidences show that women are disadvantaged when compared to men in virtually all aspects of life because of the gender differences prevail in the society (Haregwoin \& Emebet, 2002) [4]. They are deprived of equal access to education, health care, capital and decision-making power in political, social and economic sectors.

The cultural environment in Africa is among the factors that have influenced the participation rate of women and men both in the public and private spheres. Whereas there are significant local and national particularities, roles assigned to men and women are largely culturally pre-determined and different. Although in some countries measures have been taken to provide women with fundamental rights dejure such as the right to own land and to inherit property through the constitution, civil codes and statutory law, de facto, extensive discrimination against women still persists. Women's rights are still largely abrogated by customary laws and practices that exist concurrently with statutory law and are simultaneously applied. The gendered experience of poverty becomes very clear on examination of various development dimensions, in the division of labour, access to and control over resources, education, health and participation in the political arena as well as in the formal labour market. In addition, whereas Africa has the largest number of the poor in the world, it is also increasingly taking on a female character, a phenomenon that has been termed the feminization of poverty, which made its major breakthrough into the development lexicon in the 1990s.

A critical catalyst was the $4^{\text {th }}$ Nations Conference on Women at which it was asserted that $70 \%$ of the world's poor were female. Three of the most common tenets of feminization of poverty are that of women represent a disproportionate percentage of the world's poor, which this trend is deepening, and that women's increasing share of poverty is linked with a rising incidence of female household 
headship( feminization of female headed house hold (Chant, 2006) [5].

However, in terms of basic definitions and assumptions by many writers, and organizations, especially United Nations, one problem about the "feminization of poverty" is that women are either presented as a homogenous mass, or are differentiated solely on grounds of household headship. Feminization of poverty' is not only just about lack of income' rather it needs more holistic conceptual frameworks to summarize gendered privation, encompassing capabilities, livelihoods, subjectivities and the deep rooted social exclusion.

In Ethiopia, women constitute nearly half of the population. They are significantly contributing to the wellbeing of the family as well as the country. According to studies undertaken by NGOs and GOs it is estimated that Ethiopian women work for an average of 12 - 14 hours a day (Haregwoin \& Emebet, 2002) [4]. Unfortunately, however, compared to men, women in Ethiopia are clearly in a disadvantageous position in all respects; they benefit less from social services and hold inferior positions in all economic, political, social, and cultural affairs.

The data from the Federal Civil Service Agency (FCSA) on federal government employees shows that women occupy only 18.3 per cent of all professional and scientific positions, and 25 per cent of administrative positions, indicating that the upper and middle level positions in the civil service are still overwhelmingly dominated by men. According to the same source, women hold 71 per cent of clerical and fiscal jobs and 51 per cent of the custodial and manual jobs (FCSA, 2007) [6]. Looking at the health situation of women, it is noted that there are several poverty and cultural factors that negatively affect women's health, as reflected by various health indicators.

Since agriculture is the main economic base for Ethiopia, women suffer from heavy workload, especially in rural areas. They spend up to 10 hours per day in the field in the peak agricultural seasons in addition to the house works (Habtamu, Hirut, Yosuf, \& Konjit 2004) [7]. But, since plough is designated to men except female headed households, women have minimal role in decisions related to land distribution and agricultural production. They have less or no control over the assets and no access to modern technologies.

According to Haregewoin and Emebet (2002) [4], Ethiopian women hold lower status in relation to men because of the gender difference related to the following factors:

1) They are generally poorer than men because they have less control over resource and what they earn less;

2) They are less educated especially as the education ladder goes higher;

3) They are increasingly becoming heads of households, with no resources to support their dependents; According to International Labor Organization (ILO), female headed household is a household either where no adult males are present, owing to divorce, separation, migration, non-marriage or widowhood, or where men, although present, do not contribute to the household income (ILO Thesaurus, 2005) [8]. Ranjay Vardhan (1999) in his study on Female 
Headed Households in Patriarchal Society found that majority of the household heads tend to be those of widows followed by women who assume headship due to divorce and desertion which is rising in recent years in our society. Migration for labor of men not only to the other parts of the country but also to the other countries is also emerging as an important reason for the emergence of such households. The primary reason for male's migration to other states is for better life. Large percentages of migrants are dissatisfied with their jobs in domestic and while other lacks even job opportunities at their home states. Lack of job security, low wages, and poor working conditions cause frustration and uncertainty. The withdrawal of the male head of the family from the family home evidently reduces his ability and authority to control and decide, and the wife is likely to step into filling the gap.

Generally, there are various factors that contribute to the emergence of female-headed households such as economic disparities, migration, marital instability, divorce related to poverty, dysfunctional families, lack of education, irresponsible male sexual behavior, early marriage, drug abuse, etc.

4) They do not enjoy due acknowledgement for their labor contribution at public and private spheres or their contributions are under estimated, devalued;

5) They do have less decision-making power at private and public spheres.

In general, women in Ethiopia are at subordinate position in relation to men when measured in terms of educational attainment, employment and remuneration, occupational type, access to services and benefits, opportunities to participate in decision-making and politics. Although they are involved in the social, economic, cultural and political spheres, when they are compared with their male counterparts, they benefit less from their contribution and are less involved in decision-making levels.

\subsection{Gender Mainstreaming}

To effectively tackle gender inequalities, the structures and systems which act as root causes of gender inequality must be addressed. To do this there should be the mainstream of gender concerns into all policies, programmes, service delivery etc. using gender analysis to identify where structures, systems and society's stereotypical norms lead to unintentional disadvantage and discrimination on the grounds of gender. Gender Mainstreaming challenges decision-makers to question the assumption that policies and programmes affect everyone in the same way.

Gender mainstreaming is a broad strategy that aims to bring the perceptions, experiences, knowledge, priorities and interests of women as well as men into all aspects of policies, planning, implementation and monitoring of any social, political or economic action. It is strategy for making women's as well as men's concern and experiences an integral dimension of the design, implementation, monitoring and evaluation of policies and programmes in all political, economic and societal spheres so that women and men benefit equally and inequality is not 
perpetuated. The ultimate goal is to achieve gender equality.

Similarly, working definition of United Nations Development Program (UNDP) on gender mainstreaming as quoted by Joka, B \& Fetenu (1997) [9] is a process of identifying and taking full account of the relationships between men and women in all of an agency's policies, programs, administrative and financial activities at every level.

According to Machacha \& Alexander (2004) [10], mainstreaming process starts from the analysis of the purpose, mandate and functions of an institution, sector or development instrument. They also explained that mainstreaming can be beyond integration by maintaining a separate set of activities and ensuring specific areas of responsibility for gender and by outlining context specific and time bound action plans and financial commitments. This explanation indicates that gender mainstreaming is beyond the integration of women's concern in development process rather it entails addressing gender issues in all development programs or projects.

\subsection{Objectives of Gender Mainstreaming}

The first idea to grasp is that gender mainstreaming is not a goal, but a strategy to achieve gender equality. Thus, the objectives of gender mainstreaming is to ensure an equal and equitable access to resources and benefits for both men and women in order to contribute to sustainable development, to promote economic growth and poverty reduction.

According to UNESCO (2003) [11], gender mainstreaming increasingly helps to highlight the following qualities in an organization:

- The focus of equal opportunities policy, and views on equitable distribution of resources; whether policy takes account of the aspirations, interests and perceptions of men and women;

- Support for equal opportunities policy and gender mainstreaming at all levels of the organization;

- Availability of resources, both financial and human, to formulate and implement policy;

- Engendering of knowledge, skills and attitudes on emancipation and gender equality, and availability of gender expertise;

- Identification of responsibilities and accountability for gender policy and gender mainstreaming.

\subsection{The Influences of Resource Mobilization, Patriarchy and Policy Implementation on Gender Mainstreaming}

It is fact that capacity of human resources in development needs attention. There is a shortage of human resource capital in Ethiopia which is needed for successful integration of gender mainstreaming. In order to ensure that equality between men and women through the gender mainstreaming initiatives, resources should be allocated at all levels. Professionals in development projects 
and programmes need to be made aware of the necessary activities and appropriate resources needed in the development process. They also need to be provided with skills to assist them on how to plan, design, implement and control the development process.

Women can also educate and build the capacity of the end-users and the beneficiaries of the development process, especially within their communities to which management and maintenance of the services will be increasingly decentralized (Walby, 2005) [12]. People especially policy implementers need to be sensitized and encouraged to be responsive to specific needs of socio-economically vulnerable groups including marginalized groups such as women, and people with disabilities children who are mostly in rural areas (Greed, 2005) [13].

The purpose of directing resources towards gender mainstreaming is to create awareness and build the capacity of people in order for them to overcome the obstacles of development. Capacity building can be done by enhancing understanding of the background, constraints and benefits of development in different areas through the participation of both men and women (Gurung and Lama, 2003) [14].

Allocating sufficient resources towards gender mainstreaming is partially demonstrated by bringing on board the under-represented groups which in most cases women. This will enable them to take part in decision-making and ensure that they are truly part and parcel of the change process (Kwesiga and Ssendiwala, 2006). Concerning the acquisition of basic knowledge, training and skills, people may demand to be consulted, heard and be involved in development projects and programmes. It is through consultation that people's views and perceptions can contribute to development that affects them (Singh, 2006) [15].

Human and material resources form an integral part of implementing gender mainstreaming. Scarcity and lack of proper allocation have a negative impact because at the end, results will not represent the real situation on the ground (Macdonald, 2003) [16]. It is assumed that if women are provided with access to resources such as skills training, credits, small-scale income generating activities and home economics, they will improve their situation and become full economic partners with men. This will be characterized by incomegenerating projects for women with the aim of addressing the systemic causes of gender inequality (Esplen, 2006) [17].

Social institutions like families, churches and schools perpetuate the gender roles, which are the reasons why through the social structure, different power relations and status between men and women are experienced. This has resulted in gender inequality within many societies (Momsen, 2004). The different value of work based on sex creates different degrees of access and control over resources and different benefits by men and women.

From a feminist perspective patriarchy is defined as a set of social relationships which cause domination of men over women. Patriarchy is a social system and societal structure that institutionalize male physical, social and economic 
power over women. Men are regarded as the authority within the family and the community and power and possessions are passed on from father to son.

Patriarchy forms a system in which there are sets of beliefs, opinions and behavior about masculinity and feminism. This belief is mainly due to the influence of culture. Patriarchal ideology does not only vary from one culture to the other but they also vary within cultures over time (Jolly, 2002) [18]. As societies become more complex, the roles played by men and women are not only determined by patriarchal beliefs but also by socio-political and economic factors such as gender roles, socialization, division of labour, value, power relations and institutions. Gender roles are what a society or culture constructs and prescribes as proper roles, in examples of behavior and personal identity, which is associated with women is feminism and with men is masculinity, with the latter given more hierarchical value (Kirsten, 2006) [19].

For many years, patriarchy has been influenced by culture through division of labour. This refers to work done by men and women that are divided according to gender. The work performed by men is valued differently as compared to that performed by women. Men's work is recognized and valued as work by payment, status or political power, while work performed by women is seen as natural, devalued, under estimated and in most cases is not remunerated or given Status (Moreno, 2002) [20].

Women are over loaded with reproductive and communities responsibilities than men and often have no time to participate in planned development programmes and projects. The gender roles get their reinforcement from the gender division of labour. The value of work refers to the value placed on tasks. This value differs between the work that women and men do. Each role is associated with a set of behavior and values and the value attached to each role creates different access to resources and benefits (Boughelaf, 2012) [21].

The problem with women is not only the lack of participation in the development process as equal partners with men but their participation generates and perpetuate inequalities, making use of existing gender hierarchies to place women in subordinate positions at each different level of interaction between class and gender. Patriarchy should be challenged and all efforts should be directed towards liberating women (Portier, 2007) [22]. The practices of gender oppression and exploitation have been the major influencers of lagging behind of women. The manner in which men and women relate also has an influence. Though different, they all have the rights to access and control of means of production and their welfare in general. Women on the other hand can gain further support within their families and kinship.

Gender mainstreaming means that differences between women and men may never be used as a ground for discrimination and it creates a partnership between men and women to ensure that both participate equally (Moser, 2005) [23]. In many societies, there are cultural institutions, beliefs and practices that undermine women or men's autonomy and contribute to gender discrimination. 
For instance certain marriage practices which have disadvantaged families especially where customs such as dowry and bride wealth are involved have been corrupted by western consumer culture. Over the years, dowry has become an expected part of the marriage transaction.

Almost every traditional African society was patriarchal and a woman's place within this scheme was decidedly subordinate. Institutionalization of this inequality remains inter woven in African customary law. For example, in most customary systems, women have no right to inherit from their husbands and are not regarded in the sharing ownership of marital property. In this case, there is power in African traditions and norms and this could further explain the cause of domestic violence (Beck and Nesmith, 2001) [24]. Other cultural practices that perpetuate patriarchy include uneven distribution of power within traditional African marriages, the impact of polygamy, and the power of extended family over the married couple (Almoroth, 2005) [25].

Patriarchal implications of gender inequality can either be direct or indirect. These are forms of discrimination which can easily be detected at first sight. An example of the direct one is when some internal or external job advertisements states that only a specific gender in this case men, can be considered as candidates. This is direct discrimination that is explicit and is not related to a candidate's potential, ability or merit. The intention of the employer is assumed to have been directed by some form of cultural beliefs (Singh, 2006) [15].

The indirect type of patriarchy as presented by culture might seem nonexistent. It takes place when a requirement or condition is applied equally to men and women; however, the condition has the effect that in practice it disadvantages a much larger proportion of women than men (Kapur and Duvvury, 2006) [26]. Whilst the direct inequality provisions cover clear and deliberate unfair discrimination against women, those relating to indirect inequality are designed to tackle the less obvious and presumably unintentional discriminatory treatment that might arise in the course of employment (Moser, 2005) [23]. Patriarchal factors therefore, impact the process of gender mainstreaming negatively in areas such as those of employment, recruitment and promotion. It also limits organizational efficiency, wastes the potential skills of people and harms individuals at personal levels. Moreover, it has an impact on the upbringing of children who in most cases tend to learn from adults (Tsikata, 2007) [27].

A policy implementation problem is not restricted to only developing nations or to national spheres of government. Wherever and whenever the basic critical factors crucial to policy implementation are missing, whether in developed or developing nations, there is bound to be an implementation problem (Davis, 2009) [28]. Policy gaps in developing countries especially in Ethiopian arise from issues of poor implementation, corruption, lack of co-ordination, ineffective governance, centralization and the distance between policy making and practice.

Another point of focus is that gender mainstreaming should be concerned with gender relations by rethinking policy formulation through a gender lens 
rather than just adding women into the development process. It is therefore the role of government systems to create conditions that will result in equality in outcome in order to balance the unequal starting positions of men and women within communities, but this too far from reality in Ethiopia let alone talking about gender mainstreaming at all levels in Ethiopia, the country has no gender policy still.

It is not possible that all policies will equally initiate the interest of all the people. Some policies may be less stimulating than others (Brynard and de Coning, 2006) [29]. The context in which a policy is implemented contributes a crucial role in ensuring successful implementation and may perhaps be the difference between the success and failures of a policy. Policy makers should effort to adjust the policy according to the context. A policy developed without reference to social, political, economic and administrative environment could possibly cause a policy gap (Brynard, 2007).

Above all Commitment is another factor and it refers to the ability to maintain the focus of an initiative from its inception through to its delivery. For effective implementation, commitment must occur at all levels of the policy process, including policy makers and policy implementers from the top-down or bottom-up hierarchy of government departments and organizations according to (True, 2012) [30].

Capacity of the government to utilize resources is also of great consideration. Intangible resources include leadership, motivation, transparency commitment; willingness, courage, empathy and endurance are also included. Absence of adequate resources will result in implementation failure because it means that laws will not be enforced, services will not be provided and reasonable regulations will not be developed. Capacity contains of two elements namely: policy capacity and implementation capacity (Makinde, 2005) [31].

Coalitions and the ability to establish clients are equally important for effective policy implementation. The government joins coalitions of interest groups from the public and private sectors, opinion leaders and other outside actors who are supportive of the particular implementation process since power shifts can strongly influence a particular implementation process (Brynard, 2005).

Mainstreaming as a strategy in itself has no problem, but the challenge of achieving equality through mainstreaming gender highly depends on how the entire process is conducted, the skills for conducting it, the involvement of all and not just women and most of all have to commitment to work for equality.

It is clear that the greatest challenge in working with gender mainstreaming in this case therefore is lack of adequate exposure to mainstreaming. It is clear that the Ethiopian government is committed to work with gender mainstreaming, but the government institutions lack the level of know-how of working with the strategy effectively both among (Gutema and sultan, 2019) [32].

Challenges that might constraint any development process can also significantly affect gender mainstreaming practices in different public sectors. This is 
because of the fact that gender mainstreaming means continue and responsive attention to equality between men and women in development, policies, strategies and operations.

Gender mainstreaming challenges cannot be addressed only by gender focal persons assigned in public institutions alone which is as usual in Ethiopia. It was also confirmed that gender mainstreaming cannot be achieved without gender knowledge, awareness, sensitivity and analytical skills of gender issues systematic training program designed for various levels of personnel and given on continuous basis with concrete linkages to the particular sector under review is a must.

\section{Concluding Remarks}

- The Federal Democratic Republic of the constitution gives recognition for religious and customary practices. This shows that the constitution devoted for cultural diversity of the state. But these religious and customary practices are highly dominated by men therefore there is a great tendency to do in favor of men.

- The context in which a policy is implemented contributes a crucial role in ensuring successful implementation and may perhaps be the difference between the success and failures of a policy. Policy makers should have efforts to adjust the policy according to the context.

- Challenges that might constraint any development process can also significantly affect gender mainstreaming practices in different public sectors. This is because of the fact that gender mainstreaming means continuous and responsive attention to equality between men and women in development, policies, strategies and operations.

- There is a number of constraints that hinder gender mainstreaming work in Ethiopia. Some of these challenges include lack of commitment on the part of decision making bodies, lack of gender mainstreaming knowledge and understanding, lack of gender awareness and sensitivity, insufficient resources both financial and human, unclear mandate, limited amount of budgetary allocations and lack of appropriate linkages within and among other bureaus, the existence of resistance to gender equality, etc.

- Social institutions like families, churches and schools perpetuate the gender roles, which are the reasons why through the social structure, different power relations and status between men and women are experienced.

- Gender mainstreaming challenges cannot be addressed only by gender focal persons assigned in public institutions alone, mainstreaming cannot be achieved without gender knowledge, awareness, sensitivity and analytical skills of gender issues; systematic training program needs to be designed for various levels of personnel and given on continuous basis with concrete linkages to the particular sector under review is a must.

- Gender mainstreaming is a transformational process requiring changes in 
personal attitudes, behaviors and working habits of individuals within an organization. Changes in an organizational culture should be reflected in the case of gender inclusive languages and avoidance of stereotyping in communication representation and behavior.

\section{Conflicts of Interest}

The authors declare no conflicts of interest regarding the publication of this paper.

\section{References}

[1] Ogato, G.S. (2013) The Quest for Gender Equality and Women's Empowerment in Least Developed Countries: Policy and Strategy Implications for Achieving Millennium Development Goals in Ethiopia. Department of Rural Development and Agricultural Extension, Institute of Cooperatives and Development Studies, Ambo University, Ethiopia. https://doi.org/10.5897/IJSA2013.0454

[2] Tesfayenesh, L. (2008) Gender Mainstreaming in Minerals and Energy Sector, a Paper Presented at the Workshop Organized by ENDA-Ethiopia, Addis Ababa.

[3] Pathfinder (2007) Empowering Girl's and Women's for Effective Social Change.

[4] Haregewoin, C. and Emebet, M. (2002) Country Gender Profile Ethiopia. SIDA, Swedish.

[5] Chant, S.H. (2006) Re-Thinking the "Feminization of Poverty" in Relation to Aggregate Gender Indices. Journal of Human Development, 7, 201-220. https://doi.org/10.1080/14649880600768538

[6] FCSA (2006) Survey on the Status of Men and Women Employees and Recommendations and Action Plans for Gender Equality. Main Report, Unpublished, Addis Ababa.

[7] Habtamu, W., et al. (2004) Gender and Cross Cultural Dynamics in Ethiopia: The Case of Eleven Ethnic Groups. CERTWID, Addis Ababa.

[8] ILO (2005) Global Unemployment Trends for Women. ILO, Geneva.

[9] Joka. B. and Fetenu (1997) Report on Review of Gender Mainstreaming in UNDP 5 Cycle Country Program. Unpublished, Addis Ababa.

[10] Machacha and Aer Experiences and Mainstreaming in Blexander (2004) Gendotswana: Paper Presented at Planning Meeting to Launch the Program in Integrating Gender Issues in Research. Unpublished, Addis Ababa, Ethiopia.

[11] UNESCO (2003) UNESCO's Gender Mainstreaming Implementation Framework (GMIF) for 2002-2007, Paris. http://www.unesco.org/images/0013/.pdf

[12] Walby, S. (2005) Gender Mainstreaming, Productive Tensions in Theory and Practice. Social Politics, 12, 321-343. https://doi.org/10.1093/sp/jxi018

[13] Greed, C. (2005) An Investigation of the Effectiveness of Gender Mainstreaming as a Means of Integrating the Needs of Women and Men into Spatial Planning in the United Kingdom. Progress in Planning, 64, 243-321.

https://doi.org/10.1016/j.progress.2005.08.004

[14] Gurung, J. and Lama, K. (2003) Incorporating Gender into a Male Domain: A Strategy for Foresters. Quebec Publishers, Canada.

[15] Singh, N. (2006) Women's Participation in Local Water Governance: Understanding Institutional Contradictions. Gender, Technology and Development. Eastern 
Publishers, New York. https://doi.org/10.1177/097185240501000104

[16] Macdonald, M. (2003) Gender Inequality and Mainstreaming in the Policy and Practice of the UK Department for International Development. Womankind, London.

[17] Esplen, E. (2006) Engaging Men in Gender Equality Positive Strategies and Approaches. Overview and Annotated Bibliography. Bridge Institute of Development Studies, Sussex.

[18] Jolly, S. (2002) Gender and Cultural Change, Overview Report Bridge: Brighton, Institute of Development Studies.

[19] Kirsten, J. (2006) Rural Development Focusing on Small Scale Agriculture in Southern Africa. University of Pretoria Press, Pretoria.

[20] Moreno, C. (2002) Placing Gender at the Centre of Health Programming: Challenges and Limitations. Social Science \& Medicine, 54, 1713-1723. https://doi.org/10.1016/S0277-9536(01)00339-2

[21] Boughelaf, J. (2012) Women of the Egyptian Revolution. Credemus Associates Publications.

[22] Portier, J. (2007) Filling the Translation Policy in Gender Mainstreaming, Environmental Health Perspective. Grate Publications, Thailand.

[23] Moser, A. and Moser, C. (2005) Gender Mainstreaming Since Beijing: A Review of Success and Limitation in International Institutions. Journal Gender \& Development, 13, 11-22. https://doi.org/10.1080/13552070512331332283

[24] Beck, T. and Nesmith, C. (2001) Building on Poor Peoples' Capacities, the Case of Common Property Resources in India and West Africa. World Development, 29, 119-133. https://doi.org/10.1016/S0305-750X(00)00089-9

[25] Almoroth, L. (2005) Genital Mutilation of Girls in Sudan, Community and Hospital Based Studies on Female Genital Cutting. Karolinska Press, Stokholm.

[26] Kapur, A. and Duvvury, N. (2006) a Rights-Based Approach to Realizing the Economic and Social Rights of Poor and Marginalized Women. International Center of Research on Women, Washington DC.

[27] Tsikata, D. (2007) The Rights-Based Approach to Development. Potential for Change or More of the Same Institute of Statistical, Social and Economic Research, University of Ghana.

[28] Davis, G. (2009) Policy Implementation Capacity: The Case of Saldanha Bay Municipality. Administration Publica.

[29] Brynard, P. and Coning, C. (2006) Policy Implementation in Improving Public Policy, from Theory to Practice. 2nd Edition, Rosin Publishers, Pretoria.

[30] True, J. and Mintrom, M. (2001) Transnational Networks and Policy Diffusion: The Case of Gender Mainstreaming. International Studies Quarterly, 45, 27-57. https://doi.org/10.1111/0020-8833.00181

[31] Makinde, T. (2005) Problem of Policy Implementation in Developing Nations: The Nigerian Experience. Journal of Social Sciences, 11, 63-69.

https://doi.org/10.1080/09718923.2005.11892495

[32] Gutema, A. and Sultan, M. (2019) Challenges of Exercising Gender Mainstreaming: The Case of Bale Zone Public Institutions. International Journal of Political Science and Development, 7, 168-172. 